\title{
Stimulus Display Geometry and Colour Discrimination Learning by Pigeons
}

\author{
JUAN D. DELIUS, ELKE JAHNKE-FUNK \\ \& ALISON HAWKER
}

Ruhr University, Bochum

\begin{abstract}
Pigeons learned a successive conditional visual discrimination on vertically and horizontally arranged pairs of stimulus-response keys. When the discriminanda were two similar hues the pigeons' performance was significantly better on the vertical than on the horizontal task. This was also found in an experiment in which the subjects could see only monocularly. When, however, the discriminative stimuli were patterns of different orientation or markedly dissimilar hues then the performance on the horizontal task had an advantage over that on the vertical one. A horizontal advantage also obtained when similar hues were discriminated on keys clustered closely together. Pigeons thus seem more adept at solving successive conditional discriminations on horizontal than on vertical pairs of keys except when similar hues are displayed on widely separated keys where the reverse is true. It is hypothesized that colour vision inequalities due to regional retinal differentiations are responsible for this latter effect.
\end{abstract}

The perceptual and action spaces of animals and man are well known to be non-homogeneous. This fact has merited much research in the case of the human species but on the whole has received only minor attention where animals are concerned. Certain experiments dealing with the acquisition of colour discriminations in pigeons conducted by two of us suggested quite incidentally that the lay-out of stimulus displays was a variable that markedly affected performance. More specifically, the experiments indicated that in an instrumental successive two-key discrimination paradigm pigeons learned the problems faster and better when the keys were arranged one above another rather than, as is more conventional, side by side. The present paper reports experiments specifically designed to confirm this phenomenon as well as others intended to elucidate which of a number of possible explanations might apply. The results indicate that the pigeon's visual field is not homogeneous with respect to colour perception, a situation that could be expected on the basis of retinal morphology. An analogous inhomogeneity of colour vision is a 
well-established phenomenon in man where the differences between foveal and peripheral chromatic perceptions are drastic (Moreland \& Hurvich, 1972). Behavioural work on the pigeon, however, has so far failed to reveal anything more than slight non-uniformities (Granda \& Maxwell, 1979).

\section{METHOD}

Six experiments were performed using the same general method. Adult homing pigeons (Columba livia) of unknown sex were used. They were obtained from local fanciers either in Durham, England, or Bochum, Germany. In the laboratory they were housed in individual cages with a 12-hour light/12-hour dark cycle and at $180 \mathrm{C}$. They had water ad libitum but were deprived of food to reach, for the experiment, 80 per cent of their normal weight.

An operant chamber measuring $40 \times 40 \times 40 \mathrm{~cm}$ was used. One wall bore four pecking keys arranged in an upright cross pattern, one pair of keys side by side, the second pair one above the other. The diameter of the keys, which were made of frosted acrylic, was $25 \mathrm{~mm}$ ( $13 \mathrm{~mm}$ in experiment IV), and their centres were $57 \mathrm{~mm}$ (13 $\mathrm{mm}$ in experiment IV) from the midpoint of the imaginary cross. The cross's centre, in turn, was $25 \mathrm{~cm}$ above the floor of the chamber, that is, at eye level for an alert pigeon.

The stimuli were back-projected on to the keys with four Counting Instruments or Zettler in-line microprojectors. Broadband coloured stimuli were produced with various Kodak-Wratten gelatin filters (specified in Table 2 and Figure 1) placed out of the focal plane in the light-path of the microprojector channels. Pattern stimuli (vertical and horizontal rectangles) were generated with specially prepared slides positioned in the focal plane of the microprojectors. The unfiltered light of the tungsten $24 \mathrm{~V} 2 \mathrm{~W}$ microprojector bulbs $(\sim 2600 \mathrm{~K})$ served as white stimulus. Care was taken within a given experiment to equalize the stimuli projected on to the various keys that were intended to be identical. Colour filters were cut out of the same sheet, light bulbs were selected for equal light output and any remaining intensity differences reduced to less than 0.1 log units with appropriate Kodak-Wratten neutral density filters. An Evans-Avo photocell-voltmeter combination or a Gossen photometer was employed to control the success of these efforts. The stability of the adjustments was checked at the end of each experiment. Over and above the preceding adjustments the luminance of all the stimuli used in the different experiments was set with neutral density filters to be approximately $86 \mathrm{~cd} / \mathrm{m}^{2}$ using a SEI or Gossen photometer. This, of course, did not equate their brightness for the pigeons, but that is not essential for the later argumentation.

When activated, a food hopper was raised under the opening of a shelf protruding into the box $10 \mathrm{~cm}$ above the floor, out of the wall opposite to that bearing the keys. A houselight and a hopper-light were situated $35 \mathrm{~cm}$ above the shelf. Modular programming equipment placed in another room controlled all events. Separate sets of counters recorded the responses on the vertical and horizontal pairs of keys. White noise served as a sound mask.

The pigeons were trained to peck the keys illuminated with white light. To ensure that they pecked all four keys, any keys that a subject was preferentially responding to were made temporarily inoperant. At the end of the pretraining for each experiment it was checked that the subjects had no consistent preference pattern for any key or set of keys. 


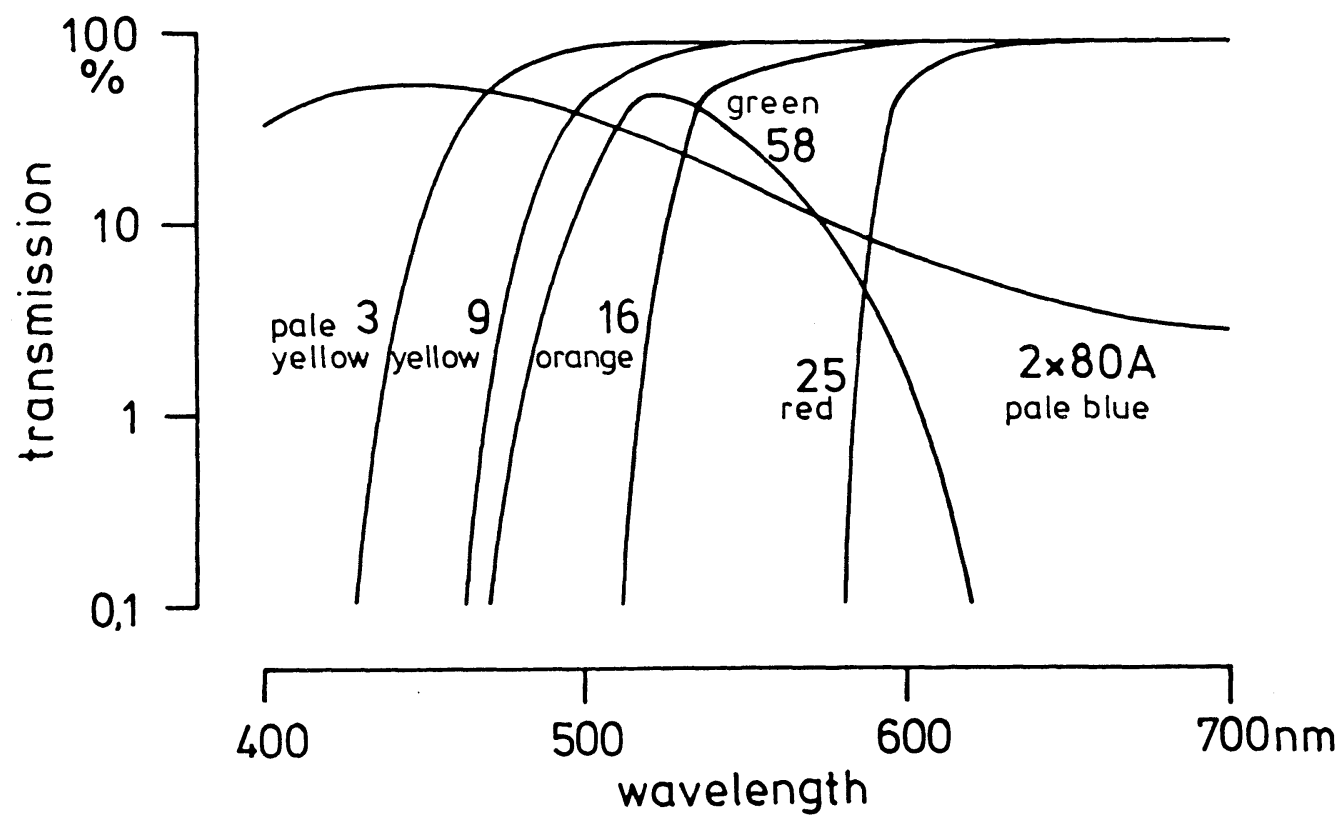

Figure 1. Spectral transmission functions of the Wratten colour filters employed in the various experiments. Redrawn from the Kodak (no date) filter handbook.

Within each experiment the subjects then learned to discriminate the same two stimuli in two different presentation modes. In one, the vertical task, the stimuli were displayed and the responses were required to be made on the vertical pair of keys. On the other, the horizontal task, the stimuli were shown and the responses were required to be made on the horizontal pair of keys. The non-illuminated pair of keys were in each case inoperant. The subjects experienced exactly the same number of learning trials with each task.

The course of events within these tasks was otherwise identical, corresponding to a successive conditional, discrete trial discrimination paradigm with correction procedure. The latter was essential because pigeons are otherwise prone, in this paradigm, to develop a position habit strategy that allows them to collect reinforcements with an 0.5 probability without discriminating. Sessions were given daily, except at weekends, to each subject and consisted of 32 trials. The horizontal and vertical tasks alternated every time eight trials on a given task were completed. A session thus included 16 trials on each task. Alternate subjects always began sessions with the horizontal task or the vertical task.

A trial began with the illumination of the pair of keys corresponding to the task due with a stimulus. In a given trial both the keys would be lit with either one or the other of the two discriminative stimuli used in the corresponding experiment (see Table 2). Which of the two stimuli was on in a given trial was determined, with a restriction to be explained below, by quasi-random sequences taken from Gellermann (1933). Either the upper or the lower and either the left or the right key were assigned as correct for one of the two stimuli. Correspondingly, the other key of each pair was deemed incorrect. The assignment for the alternative stimulus was necessarily the reverse, complementary pattern. This allocation was balanced over subjects (see Table 1) and was retained throughout the experiment. 
Table 1. Successive conditional discrimination of two stimuli (open, closed circles), alternately on a vertical pair or on a horizontal pair of keys $l_{+}=$ positive, - = negative key); see text for further details

\begin{tabular}{|c|c|c|c|c|}
\hline \multirow{3}{*}{$\frac{\text { Subjects }}{1+5}$} & \multicolumn{4}{|c|}{ Tasks } \\
\hline & \multicolumn{2}{|c|}{ Vertical } & \multicolumn{2}{|c|}{ Horizontal } \\
\hline & $\begin{array}{l}0^{+} \\
0^{-}\end{array}$ & $:$ & $0^{+} \mathrm{O}^{-}$ & $0^{-} e^{+}$ \\
\hline $2+6$ & $\begin{array}{l}\mathrm{O}^{+} \\
\mathrm{O}^{-}\end{array}$ & 0 & $\mathrm{O}^{-} \mathrm{O}^{+}$ & \\
\hline $3+7$ & $\mathrm{O}^{-}$ & & $\mathrm{O}^{+} \mathrm{O}^{-}$ & $0^{-} 0^{+}$ \\
\hline $4+8$ & $\mathrm{O}^{-}$ & & $\mathrm{O}^{-} \mathrm{O}^{+}$ & - \\
\hline
\end{tabular}

Responses to the correct key caused the stimulus to go off and food to be offered for $6.5 \mathrm{sec}$. The stimulus for the following trial was selected quasi-randomly. Responses to the incorrect key led to a darkening of the keys and the houselight for $7 \mathrm{sec}$. In accordance with the correction procedure employed, the stimulus in a following trial was now the same as in the one leading to the incorrect response, thus disregarding the Gellermann sequence. When such a correction trial led to a correct response then the stimulus of the subsequent trial was again quasi-randomly selected; if not, the correction procedure continued (unless a task changeover took place; see below). As is necessary when using such a correction procedure, only responses emitted during non-correction trials, but not those produced during correction trials, were recorded for a fair assessment of performance. Such responses incremented, separately for each task, the counters registering correct and incorrect key choices. However, all trials, non-correction and correction, contributed, again separately for each task, to the total trial count that determined the switch from one task to another, as explained earlier, thus ensuring equal learning experience with both tasks. When a task switch occurred, a possibly ongoing correction procedure was automatically interrupted. The total trial counts also brought about the termination of the session.

The basic balanced design (Table 1) was replicated using eight subjects for each experiment. The exception was experiment $V$, where only four animals equipped with a small tapped brass block cemented to their skull under anaesthesia (see Delius, Perchard \& Emmerton, 1976), were employed. An opaque, hemispherical, closely fitting cover, made of gauze fabric and acetone cement and screwed on to the brass block, was worn by these pigeons over the left eye throughout the experiment.

\section{RESULTS}

For each experiment we calculated conventional mean discrimination curves separately for the vertical and horizontal tasks. These are shown in Figure 2. For the statistical evaluation we computed the net correct responses (correct responses minus incorrect responses) delivered on each task by each subject on each session. These data were subjected to analyses of variance adequate for the repeated measures design of the experiments (Kirk, 1968). The issue of interest was the significance of the main effects due to the vertical versus horizontal treatments. This was assessed by the $F$ ratio between the variance due to the two treatments $(d . f .=1)$ 
and the residual variance (d.f. $=87$ or 246 , depending on the particular experiment). The significance values associated with these ratios are shown in Table 2 , which lists the stimuli used and summarizes the results of the various experiments.

Table 2. Stimuli, subjects and results of experiments with pigeons involving successive conditional discriminations of two stimuli alternately displayed on a horizontal or vertical pair of keys. Codes in brackets identify Kodak filters (see Figure 1). Scores are the cumulated performance differences between tasks (vertical/ horizontal). Barred scores are means of the individual scores listed. Significance levels are based on analyses of variance and $F$ tests (see text for further details)

\begin{tabular}{|c|c|c|c|c|c|}
\hline Expt & $\begin{array}{l}\text { Stimuli and } \\
\text { conditions }\end{array}$ & Subjects & Result & Score & Significance \\
\hline 1 & $\begin{array}{l}\text { Red (K } 25) v \text {. } \\
\text { orange (K 16) }\end{array}$ & 8 & $\begin{array}{l}\text { Vertical task } \\
\text { advantage }\end{array}$ & $\begin{array}{l}+53.5 \\
-6,+26,+28,+47, \\
+55,+63,+77,+138\end{array}$ & $P<0.001$ \\
\hline II & $\begin{array}{l}\text { Horizontal } v \text {. } \\
\text { vertical black } \\
\text { rectangles, } \\
6 \mathrm{~mm} \times 10 \mathrm{~mm}\end{array}$ & 8 & $\begin{array}{l}\text { Slight hori- } \\
\text { zontal task } \\
\text { advantage }\end{array}$ & $\begin{array}{l}-6.3 \\
-36,-32,-21,-19 \\
-13,+3,+24,+44\end{array}$ & $P>0.05$ \\
\hline III & $\begin{array}{l}\text { Pale blue }(2 \times \\
K 80 A) v \text {. pale } \\
\text { yellow (K 3) }\end{array}$ & 8 & $\begin{array}{l}\text { Vertical task } \\
\text { advantage }\end{array}$ & $\begin{array}{l}+19.8 \\
-44,+7,+14,+19, \\
+27,+32,+44,+60\end{array}$ & $P<0.01$ \\
\hline IV & $\begin{array}{l}\text { Red }(K 25) v \text {. } \\
\text { orange ( } K 16) \text {, } \\
\text { clustered keys }\end{array}$ & 8 & $\begin{array}{l}\text { Horizontal } \\
\text { task advantage }\end{array}$ & $\begin{array}{l}-46.1 \\
-159,-65,-55,-48, \\
-37,-32,-9,+36\end{array}$ & $P<0.001$ \\
\hline v & $\begin{array}{l}\text { Red }(K 25) v \text {. } \\
\text { yellow }(K 9) \\
\text { monocular } \\
\text { viewing }\end{array}$ & 4 & $\begin{array}{l}\text { Vertical task } \\
\text { advantage }\end{array}$ & $\begin{array}{l}+51.0 \\
+29,+35,+43,+97\end{array}$ & $P<0.01$ \\
\hline VI & $\begin{array}{l}\text { Red }(K 25) v \text {. } \\
\text { green ( } K 58)\end{array}$ & 8 & $\begin{array}{l}\text { Horizontal } \\
\text { task advantage }\end{array}$ & $\begin{array}{l}\overline{-41.0} \\
-93,-54,-50,-48, \\
-36,-33,-18,+4\end{array}$ & $P<0.001$ \\
\hline
\end{tabular}

The performance difference between tasks is suitably represented by the signed difference between the net correct response scores on the vertical and on the horizontal tasks of each session averaged across subjects. These task difference scores, cumulating over the sessions of each experiment, are shown in Figure 2. A steady upward slope indicates a persisting performance advantage of the vertical task, a downward slope an equivalent advantage of the horizontal task. An index characterizing the overall result of an experiment is the final cumulated average 
difference, and this score is given in Table 2 which also includes the corresponding individual scores. Examination of the cumulative curves in conjunction with learning curves of Figure 1 indicates that the performance differences between horizontal and vertical tasks was not only in evidence in the acquisition phase but was generally also maintained during the asymptotic discrimination phase.

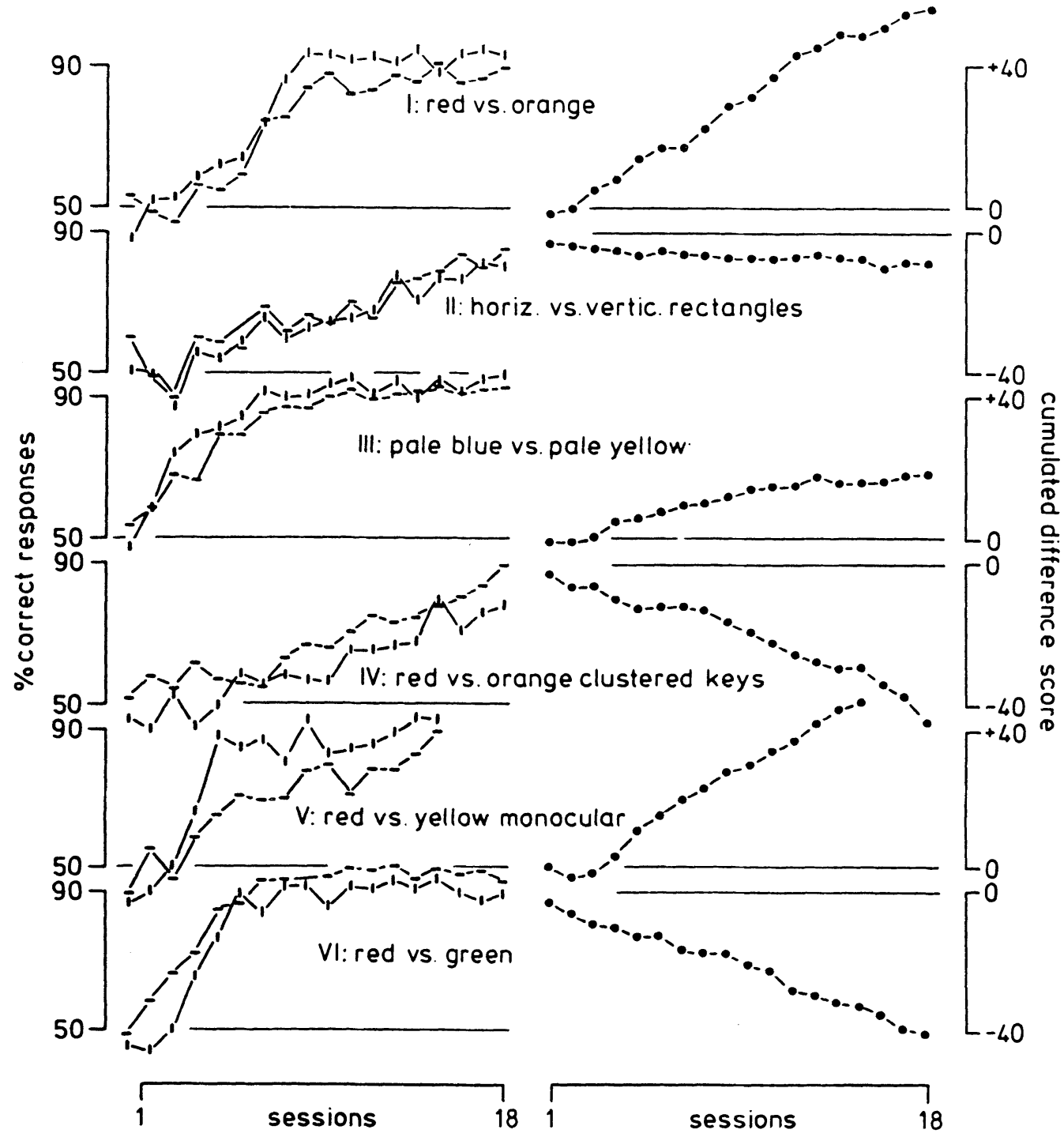

Figure 2. Results of experiments 1 to VI. Left: mean discrimination learning curves shown separately for the vertical ( 1 ) and horizontal (-) tasks. Right: mean difference index between vertical and horizontal tasks cumulating over sessions.

The hues discriminated in experiments I, III, IV and $V$ were in each case spectrally similar since the transmittance spectra of the pairs of filters used had all quite substantial overlaps. This was not so in experiment VI (red/green 
discrimination) where the stimuli were spectrally very different, the corresponding filters having a minimal transmittance overlap. Details about the characteristics of each of the filters can be gleaned from Figure 1, based on the Kodak filter handbook (Kodak, no date) information. Experiment Il involved the discrimination of the orientation of a pattern and obviously did not involve a hue difference.

\section{DISCUSSION}

The most trivial explanation for the results of the various experiments would be to assume that in spite of our efforts to equalize the stimuli over the four keys, some unintended cues might nevertheless have biased the pigeons' responses. We are satisfied that that was not the case. Slight residual intensity differences among the same stimuli projected on to different keys can be discounted, since the apparent intensity, differently from the hue, of a back-illuminated frosted key depends partially on the angle from which it is viewed. Thus intensity differences other than gross ones can be expected to be uncertain cues for the pigeons in the present arrangement. This could be verified in an unreported simultaneous discrimination experiment within the framework of this study in which an intensity difference of $0.3 \mathrm{log}$ units between keys was the intended stimulus and the performance of pigeons was found to be comparatively poor, seven of eight subjects still performing less than 75 per cent correctly by the eighteenth session. Moreover, the divergent outcomes of experiment I (red v. orange, wide-apart keys) and experiment IV (red $v$. orange, clustered keys) are at least robust: they have been replicated with less carefully adjusted stimuli and they have been shown to be resistant to stimulus projectors' being exchanged among the sets of keys in unreported experiments.

Accepting that the results are not due to artefacts, it seems that pigeons learning to discriminate pairs of similar colours, that is with extensive spectral overlaps (red v. orange, experiment I; pale yellow v. pale blue, experiment III; red $v$. yellow, experiment $V$ ) concurrently on both a vertical and a horizontal pair of widely separated keys, perform significantly better on the vertical discrimination task than on the horizontal task. This confirms the earlier preliminary findings.

A simple explanation would be to ascribe the vertical advantage effect to response polarization as the vertical and horizontal tasks involve different response geometries. Such polarity could, for example, be caused by a left/right confusion, as it is known to occur in man and some animals, although perhaps not in the pigeon (Corballis \& Beale, 1976). It cannot apply, however, since the vertical advantage is absent or even reversed when the stimuli are patterns (upright $v$. recumbent rectangles, experiment II), when an unlike hue discrimination is offered (red $v$. green, experiment VI), or when the similar hue discrimination is presented on keys positioned close together (red $v$. orange, experiment IV). The same objections arise.when other kinds of response polarization hypotheses are considered.

An alternative hypothesis can be derived from the knowledge that pigeons have a coronally narrow but sagitally elongated field of binocular vision (Chard \& Gundlach, 1938; Rochon-Duvigneaud, 1943; Martinoya, Rey \& Bloch, 1981) and from our own observations that they habitually examined the keys with an approximately upright head. From their normal aiming distance (some 6 to $10 \mathrm{~cm}$; Hodos, Leibowitz \& Bonbright, 1976, own observations; the pigeon's binocular field is known to be myopic: Nye, 1973; Marshall, Mellerio \& Palmer, 1973) they can only simultaneously 
binocularly view the vertical pair of keys but not the horizontal one (Figure 3 ).
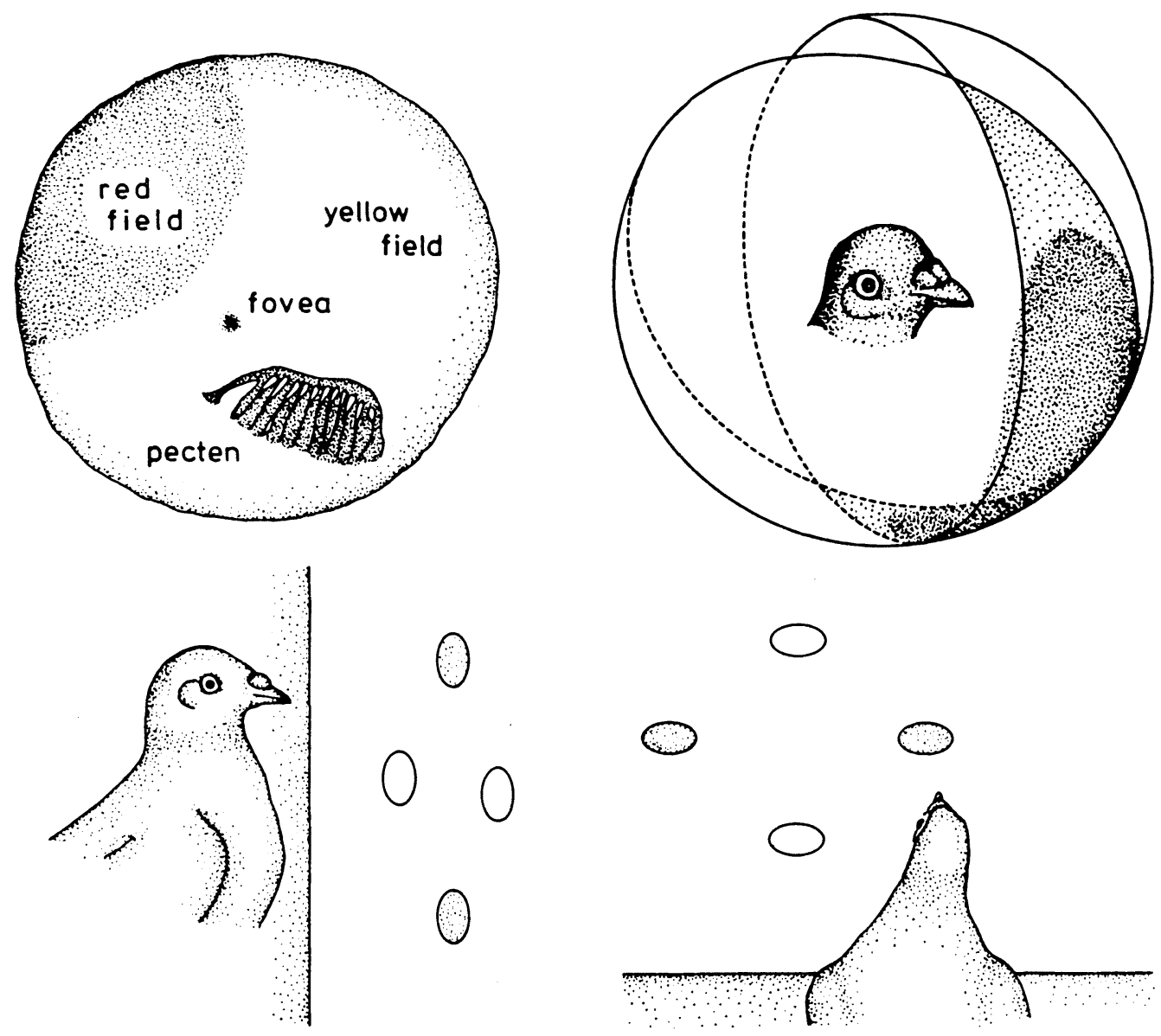

Q

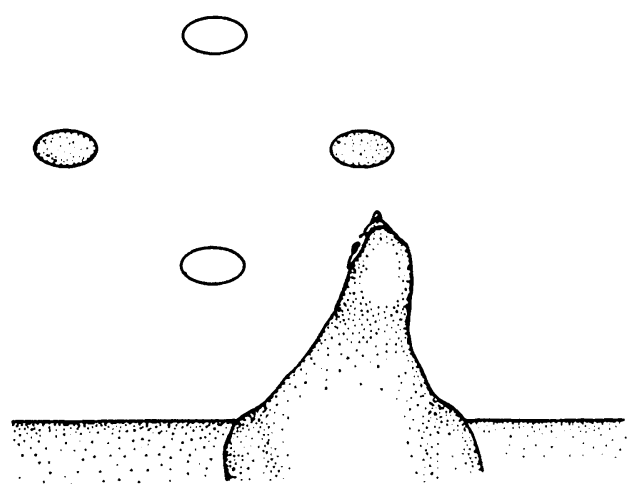

Figure 3. Top right: the visual field of a pigeon (schematic). The binocular field is stippled. The heavier stippling indicates the estimated projection of the red areas of the retinae (based on Chard \& Gundlach, 1938; Martinoya, Rey \& Bloch, 1981; personal communication, and own observations). Top left: a view of the pigeon's eye-fundus maps the extent and location of the red areas (based on Galifret, 1968, and own observations). Bottom: typical attitudes of pigeons shortly before responding to the horizontal or vertical sets of keys (drawn from photographs).

Since pigeons have virtually, if not totally, crossed optic nerves (Cowan, Adamson \& Powell, 1961; Répérant, 1973) and suffer from limited interocular transfer (Zeier, 1975; Green, Brecha \& Gazzaniga, 1978), the horizontal task, where a pigeon can view only one of the keys at a time binocularly, might be at a disadvantage. But this explanation is equally untenable as it does not conform with the dissimilar hue (experiment VI) nor the pattern (experiment II) discrimination results. Additionally, when pigeons are made to perform the similar-hue discrimination under conditions equalizing the vertical and horizontal tasks in terms of this hypothesis, that is by forcing a monocular viewing of the widely separated keys (experiment $V$ ), the vertical task advantage is nonetheless retained. 
A third hypothesis develops from the fact that the binocular field of vision of the pigeon forms images on the red areas of the retinae that are differentiated from the remainder, the yellow areas (Galifret, 1968; Martinoya, Rey \& Bloch, 1981; Bloch et al, 1979; own observations; Figure 3). These areas incorporate different sets of cones when these are classified according to the combined spectral characteristics of the photopigments and the coloured oil droplets that they contain (Bowmaker, 1977). The red and yellow areas must thus be suspected of mediating a heterogeneous perception of colour. It follows from the earlier argument that, while the pigeon can simultaneously encompass the vertically arranged keys within the red retinal fields, it cannot deal in the same way with the horizontally arranged keys. When taking aim, that is immediately before being reinforced one way or another, it can observe only one key at a time with the red fields, the other then imaging on a yellow field. The argument that the horizontal keys could have been viewed simultaneously with yellow fields from a greater distance, that is sometime before responding and receiving reinforcement, carries little weight as it is well established that the likelihood that a cue is associated with reinforcement decreases with diminishing temporal contiguity (Mackintosh, 1974).

Granting that the colour vision mediated by the two retinal fields is not equivalent, the split manner of viewing would thus inevitably introduce a subjective colour discrepancy between the two horizontal keys even though these are factually illuminated by light of identical spectral composition. The vertical task being perceived with one retinal field would not be affected by such 'illusion'. The horizontal task does thus effectively involve a spurious simultaneous discrimination superimposed on the real successive discrimination. It is well known that animals find simultaneous discrimination problems considerably easier to learn than successive ones (Mackintosh, 1974). This was confirmed within the framework of this study. The colour stimuli used in experiment VI were also used in an equivalent, unreported, simultaneous discrimination experiment. With one exception all eight subjects were performing better than 90 per cent correctly on the third session of this experiment whereas none of the eight subjects of experiment IV reached such a performance level until the seventh session. The worse horizontal task performance on the real successive discrimination can therefore be thought to have been due to the pigeons' learning about an easy but only apparent simultaneous discrimination.

All the experiments yielding no vertical task advantage support the hypothesis: the pattern discrimination (experiment II) because it did not involve colour, the clustered keys experiment (experiment IV) because it effectively removed the viewing inequalities between the vertical and the horizontal pairs of keys (all could be seen simultaneously with the red field), and the dissimilar hue experiment (experiment VI) because it minimized the interference of a spurious colour difference relatively to the real discrimination.

The results of the experiments agree with the assumption that the red and yellow areas of the pigeon's retina mediate, as one might expect from morphological data, differing perceptions of colour. Previous work, much of it ingenious, has so far only demonstrated with some certainty a slight difference between the spectral sensitivities of the two areas (Kowal, 1962; Bloch \& Maturana, 1971; Bloch \& Martinoya, 1971, 1978; King-Smith, quoted by Muntz, 1972; Nye, 1973; Romeskie and Yager, 1976; Blough, 1978; Martin \& Muntz, 1978). The present experiments can naturally contribute little to the identification of the specific colour vision differences in perceived hue, brightness or saturation that may be involved, although in view of the salience that hue appears to have for pigeons relative to the other attributes it is reasonable to assume that it is the key factor. A 
decision must await the availability of relevant psycho-physical functions for both the red and yellow fields. Spectral wavelength discrimination functions determined with the discriminanda displayed on either-widely separated horizontal or vertical pairs of keys could be instructive. They might, in fact, shed light on the disagreement that exists regarding this function as determined for the pigeon by various authors (Emmerton \& Delius, 1980).

It also emerges from the experiments that, barring interference by disconcerting subjective colour perceptions, pigeons may be more adept at solving conditional successive discriminations in terms of right/left than of up/down responses. This supports other evidence (Corballis \& Beale, 1976) that pigeons do not suffer from a dextral/sinistral confusion. The possibility that the horizontal task advantage might have been caused by other factors, such as the wider coronal extent of the pigeon's total field of view or an easier motoric access to the horizontal keys, can be reasonably excluded; these factors can hardly have played a role in the clustered keys experiment (experiment IV) that also yielded a marked horizontal task advantage.

\section{ACKNOWLEDGEMENTS}

Early parts of the work were done at the Department of Psychology, University of Durham, England. For assistance in various matters we thank students and staff at both Durham and Bochum. The research was supported by the Science Research Council, London, and the Deutsche Forschungsgemeinschaft, Bonn, through its Sonderforschungsbereich 114 .

\section{REFERENCES}

Bloch, S. \& Martinoya, C. (1971). Are colour oil droplets the basis of the pigeon's chromatic space? Vision Research Supplement, 3, 411-418.

Bloch, S. \& Martinoya, C. (1978). La discrimination chromatique chez le pigeon, varie-t-elle en fonction de la localisation rétinienne? Comptes Rendus de l'Academie de Science, Paris, 286, 1301-1303.

Bloch, S. \& Maturana, H.R. (1971). Oil droplet distribution and colour discrimination in pigeon. Nature New Biology, 234, 284-285.

Bloch, S., Rey, J. \& Martinoya, C. (1979). Tachistoscopic acuity of the pigeon's red field. Neuroscience Letters Supplement, 3, 301.

Blough, P.M. (1978). Pigeon vision psychophysics. In A.M. Granda \& G.H. Maxwell (eds.), Neural Mechanisms of Behavior in the Pigeon. New York: Plenum.

Bowmaker, J.K. (1977). The visual pigment, oil droplets and spectral sensitivity of the pigeon. Vision Research, 17, 1129-1138.

Chard, R.D. \& Gundlach, R.H. (1938). The structure of the eye of the homing pigeon. Journal of Comparative Psychology, 25, 249-272.

Corballis, M.C. \& Beale, I.L. (1976). The Psychology of Left and Right. Hillsdale: Erlbaum.

Cowan, W.M., Adamson, L. \& Powell, T.P.S. (1961). An experimental study of the avian visual system. Journal of Anatomy, 95, 545-563.

Delius, J.D., Perchard, R.J. \& Emmerton, J. (1976). Polarized light discrimination by pigeons and an electroretinographic correlate. Journal of Comparative and Physiological Psychology, 90, 560-571. 
Emmerton, J. \& Delius, J.D. (1980). Wavelength discrimination in the visible and ultraviolet spectrum by pigeons. Journal of Comparative Physiology, 141, 47-52.

Galifret, Y. (1968). Les diverses aires fonctionnelles de la rétine du pigeon. Zeitschrift für Zellforschung, 86, 535-545.

Gellermann, L.W. (1933). Chance orders of alternating stimuli in visual discrimination experiments. Journal of Genetic Psychology, 42, 206-208.

Granda, A.M. \& Maxwell, J.H. (eds.) (1979). Neural Mechanisms of Behavior in the Pigeon. New York: Plenum.

Green, L., Brecha, N. \& Gazzaniga, M.S. (1978). Interocular transfer of simultaneous but not successive discrimination in the pigeon. Animal Learning and Behaviour, 6, 261-264.

Hodos, W., Leibowitz, R. \& Bonbright, J. (1976). Near-field visual acuity of pigeons: effects of head location and stimulus luminance. Journal for the Experimental Analysis of Behaviour, 25, 129-141.

Kirk, F. (1968). Experimental Design, Procedures for the Behavioural Sciences. Belmont: Brook Cole.

Kodak, A.G. (ed.) (no date). Kodak Filter für den Berufsphotographen. Stuttgart: Kodak.

Kowal, T. (1962). Contrasted vision of colours in the pigeon, Columba domestica L. by the upper and lower part of the retina. Zeszyty Naukowe Univwersytetu Jagiellonskiego, Prace Zoologiczne Z. 6, 50, 193-216.

Mackintosh, N.J. (1974). The Psychology of Animal Learning. London: Acadernic Press.

Marshall, J., Mellerio, J. \& Palmer, D.A. (1973). A schematic eye for the pigeon. Vision Research, 13, 2449-2453.

Martin, G.R. \& Muntz, W.R.A. (1978). Spectral sensitivity of the red and yellow oil-droplet fields of the pigeon (Columba livia). Nature, 274, 620-621.

Martinoya, C., Rey, J. \& Bloch, S. (1981). Limits of the pigeon's binocular field and direction for best binocular viewing. Vision Research, 21, 1197-1200.

Moreland, J.D. \& Hurvich, L.M. (1972). Peripheral colour vision. In H. Autrum et al (eds.), Handbook of Sensory Physiology, Volume VII/4. Berlin: Springer.

Muntz, W.R.A. (1972). Inert absorbing and reflecting pigments. In H.J.A. Dartnall (ed.), Handbook of Sensory Physiology, Volume VII/L. Berlin: Springer.

Nye, P. (1973). On the functional differences between frontal and lateral visual fields of the pigeon. Vision Research, 13, 559-574.

Répérant, J. (1973). Nouvelles données sur les projections visuelles chez le pigeon (Columba livia). Journal für Hirnforschung, 14, 151-187.

Rochon-Duvigneaud, A. (1943). Les Yeux et la Vision de Vertébrés. Paris: Masson.

Romeskie, M. \& Yager, D. (1976). Psychophysical studies of pigeon color vision, I. Photopic spectral sensitivity. Vision Research, 16, 501-505.

Zeier, H. (1975). Interhemispheric interactions. In P. Wright, P.G. Caryl \& D.M. Vowles (eds.), Neural and Endocrine Aspects of Behaviour in Birds. Amsterdam: Elsevier .

PROFESSOR J. DELIUS Psychologisches Institut, Ruhr-Universität, 4630 Bochum, FR Germany. 